\title{
Investigation of molar volume and surfactant characteristics of water-soluble organic compounds in biomass burning aerosol
}

\author{
A. Asa-Awuku ${ }^{1}$, A. P. Sullivan ${ }^{2, *}$, C. J. Hennigan ${ }^{3}$, R. J. Weber ${ }^{2}$, and A. Nenes ${ }^{1,2}$ \\ ${ }^{1}$ School of Chemical and Biomolecular Engineering, Georgia Institute of Technology, Atlanta, GA, USA \\ ${ }^{2}$ School of Earth and Atmospheric Sciences, Georgia Institute of Technology, Atlanta, GA, USA \\ ${ }^{3}$ School of Civil and Environmental Engineering, Georgia Institute of Technology, Atlanta, GA, USA \\ *now at: The department of Atmospheric Sciences, Colorado State University, Fort Collins, CO, USA
}

Received: 8 February 2007 - Published in Atmos. Chem. Phys. Discuss.: 17 March 2007

Revised: 13 November 2007 - Accepted: 11 December 2007 - Published: 18 February 2008

\begin{abstract}
In this study, we characterize the $\mathrm{CCN}$ activity of the water-soluble organics in biomass burning aerosol. The aerosol after collection upon filters is dissolved in water using sonication. Hydrophobic and hydrophilic components are fractionated from a portion of the original sample using solid phase extraction, and subsequently desalted. The surface tension and CCN activity of these different samples are measured with a KSV CAM 200 goniometer and a DMT Streamwise Thermal Gradient CCN Counter, respectively. The measurements show that the strongest surfactants are isolated in the hydrophobic fraction, while the hydrophilics exhibit negligible surface tension depression. The presence of salts (primarily $\left(\mathrm{NH}_{4}\right)_{2} \mathrm{SO}_{4}$ ) in the hydrophobic fraction substantially enhances surface tension depression; their synergistic effects considerably enhance $\mathrm{CCN}$ activity, exceeding that of pure $\left(\mathrm{NH}_{4}\right)_{2} \mathrm{SO}_{4}$. From our analysis, average thermodynamic properties (i.e, molar volume) are determined for samples using our newly developed Köhler Theory Analysis (KTA) method. The molar mass of the hydrophilic and hydrophobic aerosol components is estimated to be $87 \pm 26 \mathrm{~g} \mathrm{~mol}^{-1}$ and $780 \pm 231 \mathrm{~g} \mathrm{~mol}^{-1}$, respectively. KTA also suggests that the relative proportion (in moles) of hydrophobic to hydrophilic compounds in the original sample to be 1:3. For the first time, KTA is applied to an aerosol with this level of complexity and displays its potential for providing physically-based constraints for GCM parameterizations of the aerosol indirect effect.
\end{abstract}

\section{Introduction}

Aerosols significantly impact global and regional climate. They can directly reflect the amount of incoming solar radiation into space; by acting as cloud condensation nuclei

Correspondence to: A. Nenes

(nenes@eas.gatech.edu)
(CCN), they can indirectly impact climate by affecting cloud albedo (IPCC, 2007). The ability of aerosol to act as CCN is a strong function of their size, composition and phase state. Carbonaceous compounds can constitute up to $70-90 \%$ of total aerosol mass (Andreae and Crutzen, 1997; Cachier et al., 1995; Yamasoe et al., 2000), 10-70\% of which can be water-soluble (Facchini et al., 2000; Sullivan et al., 2004; Zappoli et al., 1999). Biogenic and anthropogenic volatile organic carbon oxidation is the primary source of secondary organic aerosol in the troposphere (Kanakidou et al., 2005; Limbeck et al., 2003). Biomass burning is another major source of water-soluble organic carbon (WSOC) (Kanakidou et al., 2005; Sullivan et al., 2006); in pyrogenic air masses, WSOC can account for $45-75 \%$ of the total carbon mass (Falkovich et al., 2005; Graham et al., 2002; Mayol-Bracero et al., 2002).

WSOC is a complex mixture of neutral and acidic polar organic compounds (Decesari et al., 2000). They can affect $\mathrm{CCN}$ activity by $i$ ) providing solute, thus reducing the equilibrium water vapor pressure of the droplet and $i i$ ) acting as surfactants capable of depressing surface tension, and potentially, growth kinetics (Decesari et al., 2003; Facchini et al., 1999b; Feingold and Chuang, 2002; Kanakidou et al., 2005; Lance et al., 2004; Nenes et al., 2002; Shulman et al., 1996). Owing to its complexity, WSOC cannot be completely speciated using standard analytical methods, but instead is often characterized using "functional group analysis", using either chromatographic techniques or nuclear magnetic resonance (Decesari, 2007; Sannigrahi et al., 2006; Sullivan and Weber, 2006a; b). WSOC can be classified broadly into hydrophilic and hydrophobic fractions; these are usually operationally defined but correlate with carbon chain length and number of functional groups per molecule. Hydrophilic compounds are typically highly oxygenated low molecular weight compounds (with potentially numerous carbonyls and carboxyl groups per molecule) and tend to be highly soluble in water and exhibit limited surfactant behavior; hydrophobics can

Published by Copernicus Publications on behalf of the European Geosciences Union. 


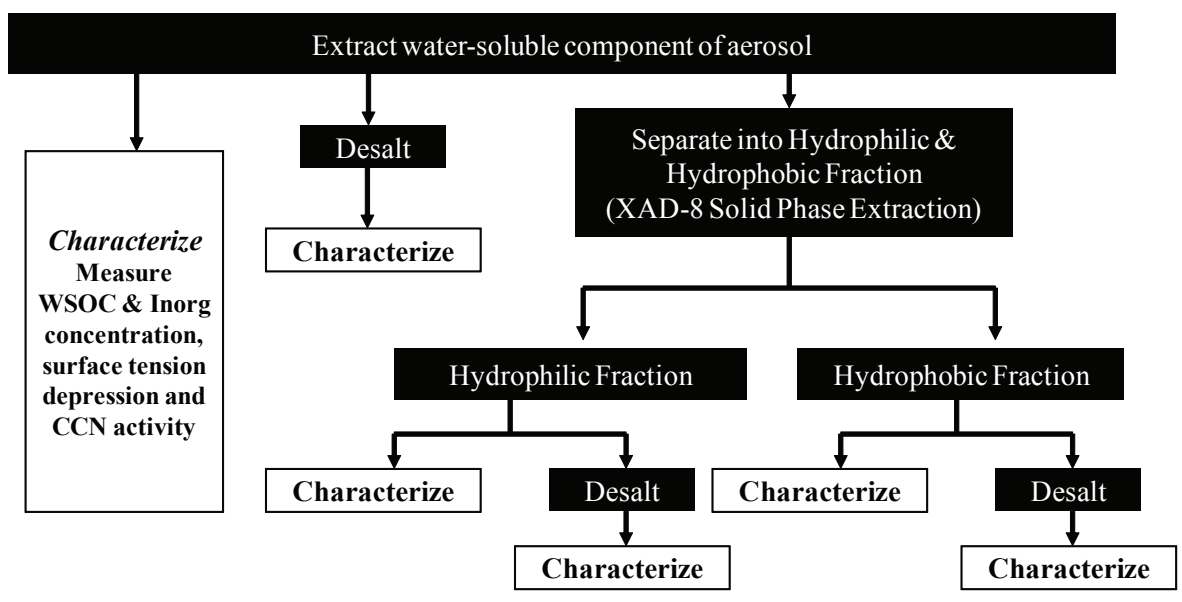

Fig. 1. Procedure used for sample analysis. The water-soluble component of the aerosol sample is extracted and characterized for carbon and inorganic content, surface tension and CCN properties. The sample is then desalted, fractionated into hydrophilic (HPHIL), hydrophobic (HPHOB), desalted hydrophilic (D-HPHIL) and desalted hydrophobic (D-HPHOB) components, all of which are characterized.

be longer in length, less hygroscopic, and strongly depress surface tension (Kanakidou et al., 2005). Surfactants have been known for a long time to be ubiquitous (e.g., Gill et al., 1983).

An important class of hydrophobic WSOC are HUmicLike Substances (HULIS); these are a mixture of high molecular weight compounds that are strong surfactants (Decesari et al., 2000; Kiss et al., 2005; Salma et al., 2006). According to Facchini et al. (2000), HULIS depressed surface tension in fog water samples by $15-20 \%$ at a $100 \mathrm{mg} \mathrm{C} \mathrm{L}^{-1}$ WSOC concentration; Kiss et al. (2005) showed that HULIS dissolved in water at a concentration of $1000 \mathrm{mg} \mathrm{L}^{-1}$ could decrease surface tension by $25-42 \%$ or even more if salts like $\left(\mathrm{NH}_{4}\right)_{2} \mathrm{SO}_{4}$ are present in solution. HULIS are present in continental aerosol, urban, rural and smog samples (Decesari et al., 2000; Facchini et al., 2000; Graham et al., 2002; Havers et al., 1998; Kiss et al., 2005; Krivacsy et al., 2000). Despite their importance, the thermodynamic properties of HULIS (e.g., average molecular weight, molar volume, solubility) is poorly constrained. This is largely due to the complexity of HULIS, which do not have a definite chemical structure, but are often described as a "network" of compounds binding together in solution, potentially forming oligomers and macromolecules (Graber and Rudich, 2006; Kalberer, 2006; Kalberer et al., 2004; Kiss et al., 2003). Due to its complexity and ubiquity, HULIS is of particular interest and has been the focus of several recent research studies (e.g., Dinar et al., 2006a, 2006b, 2007, 2008, Gysel et al., 2004; Kiss et al., 2005; Salma et al., 2006; Samburova et al., 2005; Wex et al., 2007; Ziese et al., 2007).

Comprehensively linking carbonaceous aerosol with clouds in aerosol-cloud-climate interaction studies requires knowledge of properties relevant for predicting $\mathrm{CCN}$ activity and droplet growth kinetics; these are molar volume (mo- lar mass over density), solubility, effective van't Hoff factor, and water vapor uptake coefficient. Such information, for the complex mixture of organics typical of ambient aerosol does not exist, and few methods until recently were available for obtaining it. A new method, "Köhler Theory Analysis" (KTA) (Padró et al., 2007), promises to fill this gap. There are several single parameter methods, also based on Köhler theory, that can characterize CCN activity (Petters and Kreidenweis, 2007; Rissler et al., 2006; Wex et al., 2007). KTA aims to constrain more properties, being the average (effective) molar volume, surfactant characteristics, and solubility of a water soluble organic mixture, based on measurements of CCN activity and surface tension combined with an analysis based on Köhler Theory. KTA has been successfully applied for laboratory-generated organic-inorganic mixtures of known composition; the method inferred molar volume for the organic constituents within $20 \%$ of the expected value (Padró et al., 2007). KTA has also been successfully applied to infer molar volumes of secondary organic aerosol (SOA) from the ozonolysis of alkenes (Asa-Awuku et al., 2007) and dissolved organic matter from seawater (Moore et al. 2008) ${ }^{1}$.

In this study, a biomass burning sample acquired during a prescribed burning event in Georgia (Sullivan and Weber, 2006b), is fractionated into hydrophilic and hydrophobic components to assess their individual contribution to surface tension depression and CCN Activity. Average molar volumes are inferred from KTA the surfactant characteristics are determined and the relative amounts of hydrophobic and hydrophilic compounds are found.

\footnotetext{
${ }^{1}$ Moore, R. H., Ingall, E. D., Sorooshian, A., and Nenes, A.: Molar Mass, Surface Tension, and Droplet Growth Kinetics of Marine Organics from Measurements of CCN Activity, Geophys. Res. Lett., in review, 2008.
} 
Table 1. Composition in each sample considered in this study.

\begin{tabular}{lllll}
\hline Sample & $\begin{array}{l}{ }^{\mathrm{a}} \mathrm{WSOC} \\
\left(\mathrm{mg} \mathrm{C} \mathrm{L}^{-1}\right)\end{array}$ & $\begin{array}{l}\mathrm{b}^{\mathrm{b}} \mathrm{Cl}^{-} \\
\left(\mu \mathrm{g} \mathrm{L}^{-1}\right)\end{array}$ & $\begin{array}{l}{ }^{\mathrm{b}} \mathrm{SO}_{4}^{2-} \\
\left(\mu \mathrm{g} \mathrm{L}^{-1}\right)\end{array}$ & $\begin{array}{l}\mathrm{b}_{\mathrm{NO}_{3}^{-}} \\
\left(\mu \mathrm{g} \mathrm{L}^{-1}\right)\end{array}$ \\
\hline BB & 850 & 17510 & 19698 & 20834 \\
HPHIL & 40 & 399031 & 7700 & 0 \\
HPHOB & 375 & 4058 & 27 & 0 \\
D-BB & 600 & 2438 & 4056 & 3310 \\
D-HPHIL & 130 & 7.5 & 15.3 & 0 \\
D-HPHOB & 450 & 15.6 & 53.8 & 0 \\
\hline
\end{tabular}

a The uncertainty of WSOC measurements is $3-5 \%$.

b The uncertainty is 40,200 , and $133 \mu \mathrm{g} \mathrm{L}^{-1}$ for $\mathrm{Cl}^{-}, \mathrm{SO}_{4}^{2-}$, and $\mathrm{NO}_{3}^{-}$measurements, respectively.

\section{Experimental methods}

Fine Biomass Burning (BB) particulate matter $\left(\mathrm{PM}_{2.5}\right)$ was collected on pre-baked quartz fiber filters with a Thermo Anderson Hi-Volume Air Sampler during a prescribed burning in Augusta, Georgia at Fort Gordon and in Columbus, Georgia at Fort Benning, which are both located in heavily wooded areas, in April 2004 (Lee et al., 2005; Sullivan and Weber, 2006b). Sampling and filter collection methods can be found in Lee et al. (2005). The freshly burned biomass aerosol is subsequently extracted in water, and fractionated into hydrophobic and hydrophilic fractions. Figure 1 outlines the procedure adopted to characterize the original and fractionated samples. Each step is described in subsequent sections.

\subsection{Extraction and fractionation of biomass burning sample}

WSOC is extracted with $125 \mathrm{ml}$ of pure water from the filter by sonication in a heated water bath $\left(\sim 60^{\circ} \mathrm{C}\right)$ (Baumann et al., 2003; Sullivan and Weber, 2006b) for $1.25 \mathrm{~h}$. A portion of this sample (BB) was then fractionated into hydrophilic (HPHIL) and hydrophobic (HPHOB) components using a macro-porous nonionic resin (XAD-8) Solid Phase Extraction (SPE) column (Duarte and Duarte, 2005; Sullivan and Weber, 2006a). With the WSOC solution adjusted to $\mathrm{pH}=2$ using $\mathrm{HCl}$, the resin does not retain hydrophilic compounds. Calibrations suggest this includes saccharides, amines, and carbonyls and aliphatic monocarboxylic/dicarboxylic/oxocarboxylic acids with less than 4 or 5 carbons, or hydrophobic compounds with pKa less than 2 . The column retains the long and short-chained hydrophobic compounds, which calibrations suggest may be aromatic acids, phenols, organic nitrates, cyclic acids, carbonyls and monocarboxylic and dicarboxylic chains greater than 3 to 4 carbons (Sullivan and Weber, 2006a). The column is then eluted to $\mathrm{pH} 13$ and a large amount of the adsorbed hydrophobic fraction is removed. The recovered hydrophobic fraction is adjusted to $\mathrm{pH} 2$ with $\mathrm{HCl}$ to avoid the oxidation
Table 2. Average $\alpha$ and $\beta$ parameters of the Szyszkowski-Langmuir model for all samples considered.

\begin{tabular}{lll}
\hline Sample & $\alpha\left(\mathrm{mN} \mathrm{m}^{-1} \mathrm{~K}^{-1}\right)$ & $\beta^{\mathrm{c}}\left(\mathrm{L} \mathrm{mg}^{-1}\right)$ \\
\hline BB & 2.78 & $1.72 \times 10^{-6}$ \\
HPHIL & 1.00 & $5.78 \times 10^{-7}$ \\
HPHOB & 9.18 & $6.02 \times 10^{-6}$ \\
D-HPHIL & $1.54 \times 10^{-1}$ & $8.23 \times 10^{-6}$ \\
D-HPHOB & 6.98 & $4.62 \times 10^{-6}$ \\
\hline
\end{tabular}

${ }^{\mathrm{c}}$ Measurements obtained between 296 and $299 \mathrm{~K}$.

of organic compounds. Of the compounds tested, aromatic acids and phenols had the largest recoveries. The hydrophobic compounds retained on the column at $\mathrm{pH} 2$ and recovered at $\mathrm{pH} 13$ exhibit a dark brown color, suggestive of HULIS (Graber and Rudich, 2006). Speciation methods have shown that HULIS in WSOC can be found within the hydrophobic fraction (Decesari et al., 2000; Kiss et al., 2001; Krivacsy et al., 2001; Sullivan and Weber, 2006a).

Part of the BB, HPHOB and HPHIL components are subsequently de-salted with single-use Oasis ${ }^{\circledR}$ HLB Extraction Cartridges (Waters, Milford, Massachusetts), to reduce the concentration of electrolytes in the samples. Most organics are retained on the resin while inorganic ions pass through. The organics are subsequently eluted with $100 \%$ high-purity methanol (Romil, Cambridge, UK). This eluate is dried under a gentle stream of nitrogen gas to remove the methanol and re-dissolved with $18 \mathrm{Mohm}$ ultrapue water. The desalted samples will be referred to as D-HPHOB, D-HPHIL and DBB (Table 1).

It should be noted that there can be a potential for artifacts in the fractionation process. During the desalting, low molecular weight organic compounds (i.e. acetic and formic acid) that do not strongly adsorb on the resin may pass through the chromatography column. Hence only when comparing the hydrophilics will the D-HPHIL sample, compared to HPHIL, be somewhat enriched in higher molecular weight organics. In addition, not all hydrophobic compounds are recovered from the column. Based on calibrations (Sullivan and Weber, 2006a), carbonyls and carboxylic acids greater than roughly C5 and organic nitrates are thus most likely to be underrepresented in this analysis.

\subsection{Measurement of chemical composition}

The WSOC content of the original, fractionated and desalted samples (Table 1) were measured with a Total Organic Carbon (TOC) Analyzer (Sievers Model 800 Turbo, Boulder, CO). A detailed description of the method can be found in Sullivan and Weber (2006a). We also measure anions $\left(\mathrm{SO}_{4}^{2-}, \mathrm{Cl}^{-}\right.$and $\left.\mathrm{NO}_{3}^{-}\right)$and cations $\left(\mathrm{Na}^{+}, \mathrm{NH}_{4}^{+}, \mathrm{Mg}^{+}\right.$, $\mathrm{Ca}^{2+}, \mathrm{K}^{+}$) with a Dionex DX-500 ion chromatograph with 


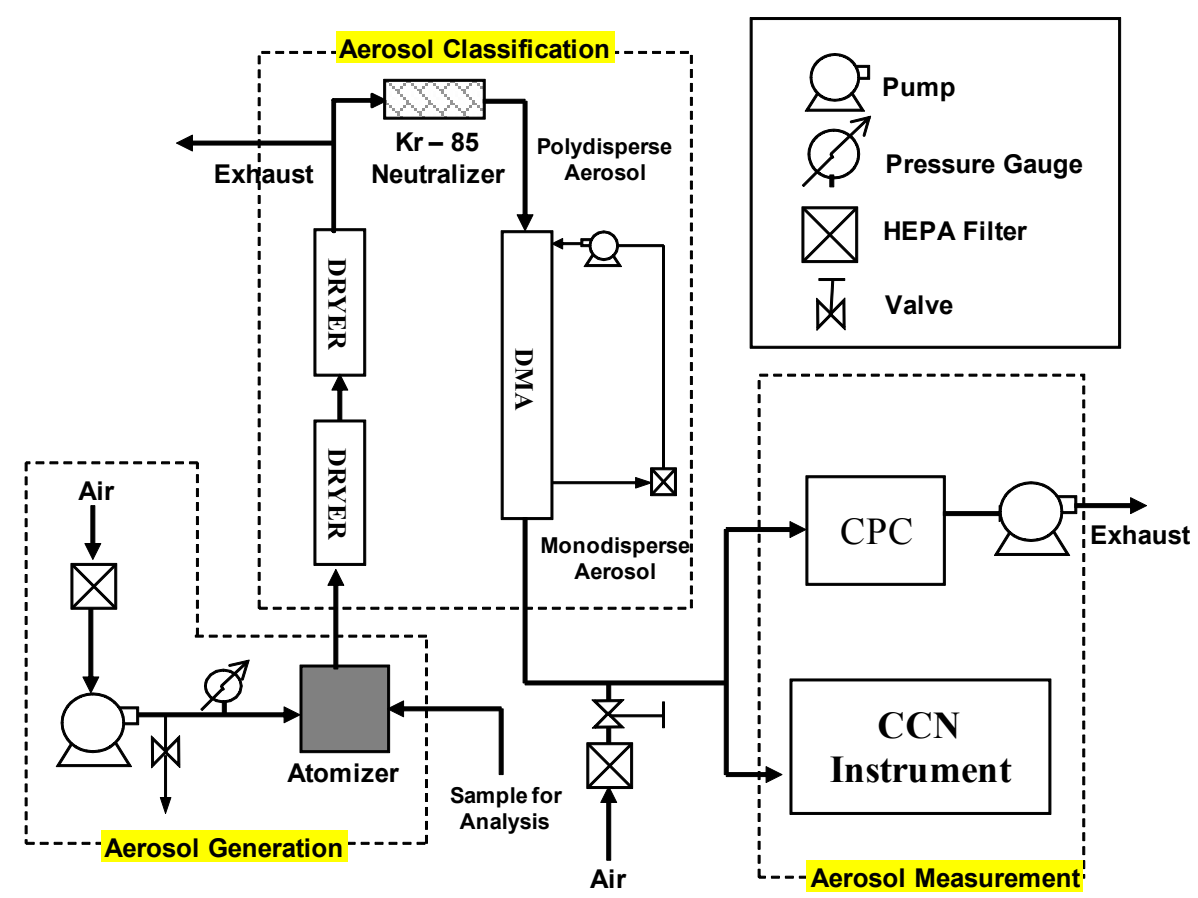

Fig. 2. Experimental setup for measuring CCN activity. Atomized sample is dried, charged and classified with a DMA. The classified aerosol stream is split into the $\mathrm{CPC}$ and the $\mathrm{CCN}$ instrument.

$\mathrm{Na}_{2} \mathrm{CO}_{3} / \mathrm{NaHCO}_{3}$ eluent and a Metrosep A Supp 5-100 analytical column (Metrohm, Switzerland). In the original and fractionated samples, ammonium was in excess, suggesting that all the organic and inorganic acids were neutralized.

\subsection{Surface tension measurements}

All surface tension measurements were performed using the pendant drop method with a KSV CAM 200 optical contact angle and surface tension goniometer. The surface tension at the liquid-air interface, $\sigma$, depends on the density jump across the interface, the gravitational constant, the radius of the droplet and the contact angle between the droplet and needle used for forming the pendant drop. The drop is allowed to equilibrate for 30-100 s, providing enough time so that large molecules (i.e., HULIS) equilibrate with the drop surface layer (Asa-Awuku and Nenes, 2007; Taraniuk et al., 2007). Fifty pendant drops were used for each surface tension measurement, requiring in total less than $200 \mu \mathrm{L}$ of sample; the $\sigma$ for commercial ultrafine de-ionized ultra-filtered water (Fischer-Scientific, W-2) was measured in between organic samples and were found to agree consistently within $2 \%$ of reported literature values at room temperature. This ensures that cross-contamination between samples did not occur. The temperature was measured with a $50 \mathrm{~K} \mathrm{Ohm}$ Thermoresistor (Digikey ERT-D2FHL503S) thermocouple.

The surfactant characteristics for each sample (Table 2) were characterized by measuring surface tension as a func- tion of dissolved carbon concentration (at the original sample concentration, then at 1:1,1:2, 1:3 and 1:4 dilution with 18-Mohm ultrapure water). The measurements were then fit to a Szyszkowski-Langmuir (Langmuir, 1917) adsorption isotherm which expresses $\sigma$ as a function of the soluble carbon,

$\sigma=\sigma_{w}-\alpha T \ln (1+\beta c)$

where $c$ is the concentration of soluble carbon $\left(\mathrm{mg} \mathrm{C} \mathrm{L}^{-1}\right)$, $\alpha$ and $\beta$ are empirical constants, obtained from least square fitting to $\sigma$ measurements, and $\sigma_{w}$ is the surface tension of 18-Mohm ultrapure water at the experiment temperature. If the surfactant is composed of a single compound, Eq. (1) describes a Gibbs adsorption isotherm of the partitioning of surfactant between the bulk and droplet surface layer, $\alpha$ and $\beta$ are related to the orientation of dissolved molecules and their interactions at the surface interface (Langmuir, 1917). Even though WSOC is a complex mixture of compounds, Eq. (1) still reproduces the measurements very well (Fig. 4). Table 2 is a summary of $\alpha$ and $\beta$ parameters obtained from fitted $\sigma$ data for the original biomass burning and fractionated samples.

In addition to measurements of the original and extracted samples, we also measured the effect of adding electrolytes on surface tension; limited by the amount of fractionates available, we performed this exercise on the original BB sample. The concentration of carbon was kept constant at $850 \mathrm{mg} \mathrm{L}^{-1}$ and premeasured amounts of electrolytes were 
dissolved. $\left(\mathrm{NH}_{4}\right)_{2} \mathrm{SO}_{4}$ and $\mathrm{NaCl}$ were used in these experiments, typical of ionic species found in the atmosphere.

\subsection{CCN activity measurements}

Aerosol generated from the original BB sample and fractions were activated into cloud droplets to determine their CCN activity. 80 to $100 \mu \mathrm{L}$ of organic sample were placed in $3-5 \mathrm{ml}$ of commercial ultrafine de-ionized ultra-filtered water (Fischer-Scientific, W-2) and atomized with a collisiontype (University of Minnesota) atomizer (Fig. 2) operated at $3.5 \mathrm{psig}$ pressure. The polydisperse droplets are subsequently dried (to $\sim 10 \%$ relative humidity) by passing them through two silica gel dryers (Fig. 2), neutralized by a Kr-85 bipolar ion source and classified using a Differential Mobility Analyzed (DMA 3081) (Fig. 2). The classified aerosol is then split and passed though a TSI 3010 Condensation Particle Counter (CPC) for measuring aerosol number concentration, $(\mathrm{CN})$. $\mathrm{CCN}$ concentrations were measured in the other stream by a Droplet Measurement Technologies ContinuousFlow Streamwise Thermal Gradient CCN Counter (STGC) (Lance et al., 2006; Roberts and Nenes, 2005).

$\mathrm{CCN}$ activity of the aerosol was characterized as follows. For a fixed supersaturation the "activation curves" (i.e., ratio of $\mathrm{CCN}$ to $\mathrm{CN}$ ) was measured between 10 and $250 \mathrm{~nm}$ dry mobility diameter. Activation ratios are then determined from $0.2 \%$ to $1.0 \%$ supersaturation. Figure 3 shows an example of activation curves obtained for D-HPHIL activation. The activation curves are then fit to a sigmoidal curve, neglecting the impact of doubly charged particles which appear as a characteristic secondary peak to the left of the main sigmoid (Fig. 3). The particle dry diameter size, $d$, at which $50 \%$ of the particles were $\mathrm{CCN}$ represent the dry diameter of the particle with critical supersaturation equal to the instrument supersaturation. The dependence of $d$ with respect to supersaturation can be used to infer solute molar volume and the presence of surfactants using KTA (Sect. 3) (Padró et al., 2007).

\section{Description of Köhler theory analysis}

\subsection{Single component CCN theory}

Each particle requires a discrete amount of water vapor supersaturation to activate into cloud droplets. This "critical supersaturation", $s_{c}$, for simple (water-soluble) singlecomponent aerosol is given by (Köhler, 1936; Seinfeld and Pandis, 1998),

$s_{c}=\left(\frac{4 A^{3}}{27 B}\right)^{1 / 2}, A=\left(\frac{4 M_{w} \sigma}{R T \rho_{w}}\right), B=\left(\frac{6 n_{s} M_{w} v}{\pi \rho_{w}}\right)$

where $M_{w}, \rho_{w}$ are the molecular weight and density of water, respectively, $R$ is the universal gas constant, $n_{s}$ are the moles of solute dissolved in the droplet, $v$ is the effective

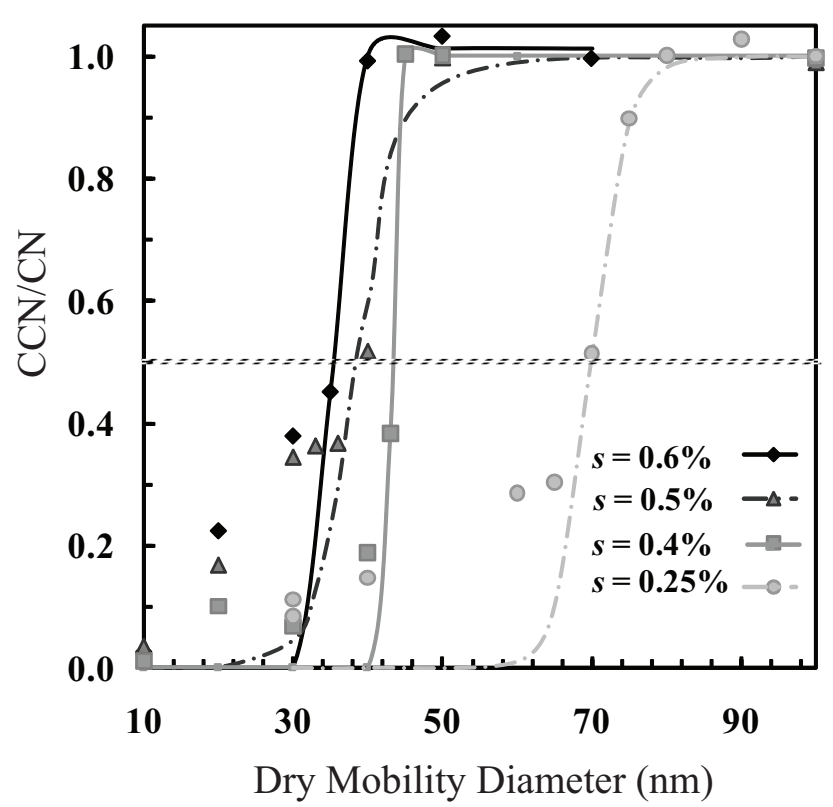

Fig. 3. Example of $\mathrm{CCN} / \mathrm{CN}$ data (D-HPHIL) with their corresponding sigmoidal fits.

van't Hoff factor of the solute, $T$ is the ambient temperature and $\sigma$ is the droplet surface tension at the point of activation. Single-component Köhler theory can be aptly applied to soluble inorganic salts and has been successfully applied to soluble low molecular weight organics as well (Cruz and Pandis, 2000; Facchini et al., 1999a; Raymond and Pandis, 2002).

\subsection{Multi-component CCN theory}

For multi-component CCN, the contribution of solute from each organic and inorganic component can be accounted for as a modification of the Raoult term ( $B$ term in Eq. 2 ) as:

$B=\sum_{i} B_{i}$

$=\sum_{i}\left(\frac{\rho_{i}}{\rho_{w}}\right)\left(\frac{M_{w}}{M_{i}}\right) \varepsilon_{i} v_{i} d^{3}$

$=d^{3}\left(\frac{M_{w}}{\rho_{w}}\right) \sum_{i}\left(\frac{\rho_{i}}{M_{i}}\right) \varepsilon_{i} v_{i}$

where $d$ is the dry diameter of the $\mathrm{CCN}$, and $\rho_{i}, \varepsilon_{i}, v_{i}, M_{i}$ are the density, volume fraction, effective van't Hoff factor and molar mass of the solute $i$, respectively. $\varepsilon_{i}$ is related to the mass fraction of $i, m_{i}$, as

$\varepsilon_{i}=\frac{m_{i} / \rho_{i}}{\sum_{i} m_{i} / \rho_{i}}$

$m_{i}$ are obtained from measurements of chemical composition. For a single component, $\varepsilon_{i}=1$ and Eq. (3) reduces to Eq. (2). 


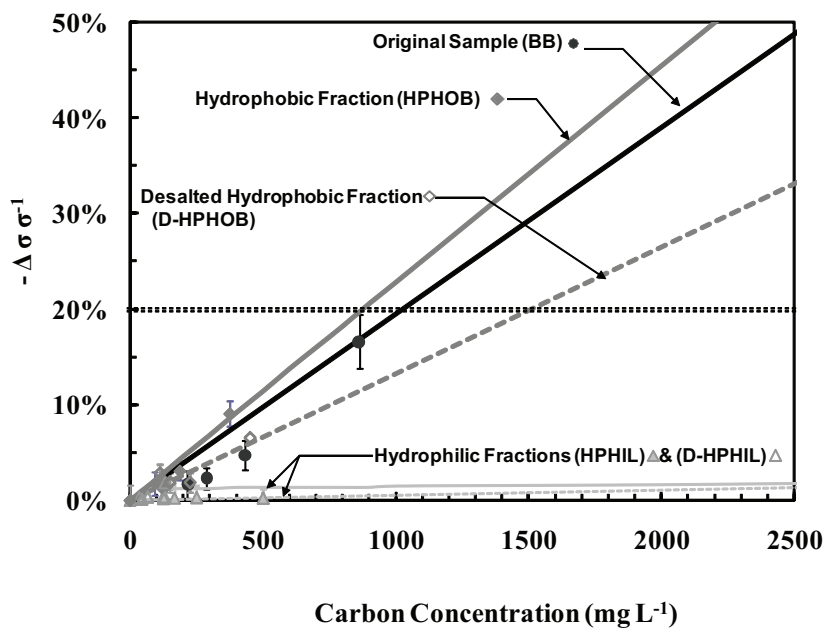

Fig. 4. Surface tension of fractionated biomass burning samples. Curves represent Szyszkowski-Langmuir fit. The original sample (solid black), hydrophobic (dark grey), and hydrophilic fractions (light grey) are shown. The desalted components are represented by dashed lines. The double dashed line indicates a surface tension depression of $20 \%$.

\subsection{Köhler theory analysis of ambient CCN}

Assuming that all solute dissolves, Eq. (2) can be written as

$$
s_{c}=\left(\frac{256 M_{w}^{3} \sigma^{3}}{27 R^{3} T^{3} \rho_{w}^{3}}\right)^{0.5}
$$$$
\left[\sum_{i}\left(\frac{M_{w}}{\rho_{w}}\right)\left(\frac{\rho_{i}}{M_{i}}\right) \varepsilon_{i} v_{i}\right]^{-0.5} d^{-1.5}=\omega d^{-1.5}
$$

where

$\omega=\left(\frac{256 M_{w}^{3} \sigma^{3}}{27 R^{3} T^{3} \rho_{w}^{3}}\right)^{0.5}\left[\sum_{i}\left(\frac{M_{w}}{\rho_{w}}\right)\left(\frac{\rho_{i}}{M_{i}}\right) \varepsilon_{i} v_{i}\right]^{-0.5}$

The molar volume of the organic component, $\left(\frac{M_{j}}{\rho_{j}}\right)$, is explicitly solved for by rearranging Eq. (6):

$$
\frac{M_{j}}{\rho_{j}}=\frac{\varepsilon_{j} v_{j}}{\frac{256}{27}\left(\frac{M_{w}}{\rho_{w}}\right)^{2}\left(\frac{1}{R T}\right)^{3} \sigma^{3} \omega^{-2}-\sum_{i \neq j} \frac{\rho_{i}}{M_{i}} \varepsilon_{i} v_{i}}
$$

where $j$ is used to denote the organic constituent and all other components $i$ refer to the inorganic components present in the aerosol. Equation (7) is the basis of KTA (Padró et al., 2007). In this study, KTA is applied as follows:

1. If there are no strong surfactants present (i.e., the surface tension of the CCN does not depend on the concentration of solute at the point of activation), $\omega$ does not depend on $d$ and its value can be determined from a

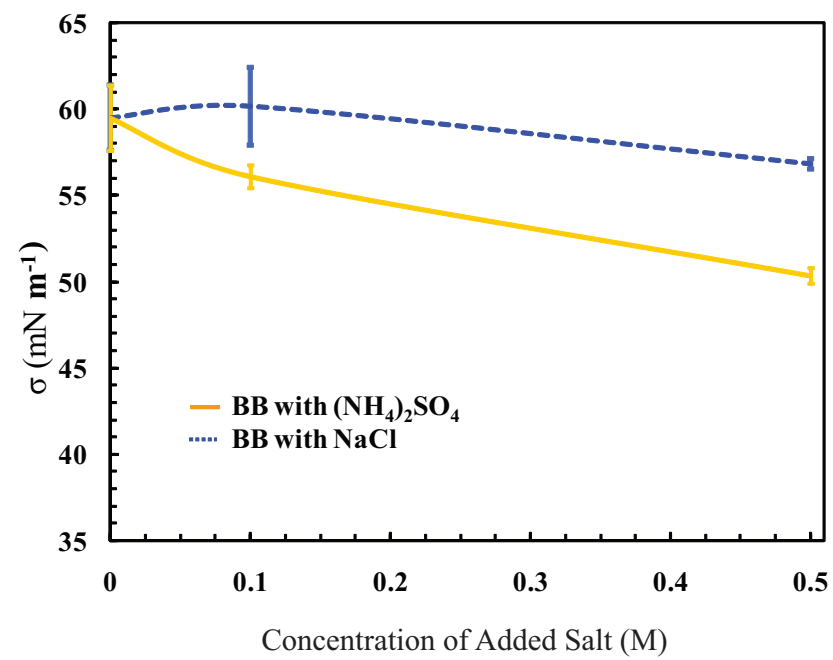

Fig. 5. Surface Tension of $B B$ sample with the addition of $\left(\mathrm{NH}_{4}\right)_{2} \mathrm{SO}_{4}$ and $\mathrm{NaCl}$. WSOC concentration is constant at $850 \mathrm{mg}$ $\left.\mathrm{L}^{-1}\right)$.

power law fit between measured $s_{c}$ and $d$ (Table 3). Application of Eq. (7) then infers the average molar volume of the water-soluble organics, provided that the volume fractions of all constituents are measured (from WSOC for organics and IC for inorganics) and the composition of the inorganics are known.

2. If there are strong surfactants present (i.e., the surface tension of the $\mathrm{CCN}$ does depend on the concentration of solute at the point of activation), $\omega$ depends on $d$, so method "a" cannot be used to infer the molar volume. Instead, two alternate methods can be used:

\subsubsection{Method $b_{1}$ ("Dilute regime")}

Since $\omega$ depends weakly on $d$ at low supersaturation (because the $\mathrm{CCN}$ are dilute enough at the point of activation so that surface tension is approximately constant) method "a" can be used for a subset of the activation experiments. The appropriate supersaturation range can be determined from the experimental data, by examining the slope of $s_{c}$ vs. $d$.

\subsubsection{Method $b_{2}$ ("Concentrated regime")}

In this case, the $\mathrm{CCN}$ can not be assumed to be dilute at the point of activation (high supersaturations), the WSOC molar volume is inferred at each supersaturation (dry diameter), using the relevant value of surface tension. We then compute the average molar volume over the range of supersaturations considered. 
Table 3. Properties used for Köhler Theory Analysis of all samples.

\begin{tabular}{lrrr}
\hline Property (units) & BB & D-HPHIL & D-HPHOB \\
\hline$\sigma\left(\mathrm{N} \mathrm{m}^{-1}\right)$ & $6.83 \times 10^{-2}$ & $6.85 \times 10^{-2}$ & $3.53 \times 10^{-2}$ \\
$\omega\left(\mathrm{m}^{1.5}\right)^{\mathrm{d}}$ & $7.78 \times 10^{-14}$ & $3.86 \times 10^{-14}$ & $6.26 \times 10^{-14}$ \\
$\nu_{(\mathrm{NH})_{4} \mathrm{Cl}}$ & 2 & 2 & 2 \\
$\nu_{\left(\mathrm{NH}_{4}\right)_{2} \mathrm{SO}_{4}}$ & 3 & 3 & 3 \\
$\nu_{\left(\mathrm{NH}_{4}\right) \mathrm{NO}_{3}}$ & 2 & 2 & 2 \\
$\varepsilon_{\left(\mathrm{NH}_{4}\right) \mathrm{Cl}}$ & 0.018 & 0 & 0 \\
$\varepsilon\left(\mathrm{NH}_{4}\right)_{2} \mathrm{SO}_{4}$ & 0.019 & 0 & 0 \\
$\varepsilon_{\left(\mathrm{NH}_{4}\right) \mathrm{NO}_{3}}$ & 0.019 & 0 & 0 \\
$\varepsilon_{\text {organic }}$ & 0.94 & 1 & 1 \\
$\nu_{\text {organic }}$ & 1 & 2.5 & 1 \\
\hline
\end{tabular}

d obtained only for the data with $s_{c} \leq 0.6 \%$.

\subsection{Molar volume sensitivity analysis}

The uncertainty in inferred organic molar volume, $\Delta\left(\frac{M_{j}}{\rho_{j}}\right)$, is quantified as

$\Delta\left(\frac{M_{j}}{\rho_{j}}\right)=\sqrt{\sum_{\text {for all } x}\left(\Phi_{x} \Delta x\right)^{2}}$

where $\Phi_{x}$ is the sensitivity of molar volume to each of the measured parameters $x$ (i.e., any of $\sigma, \omega, \varepsilon_{i}, \varepsilon_{j}, v_{i}$, and $v_{j}$ )

$$
\Phi_{x}=\frac{\partial}{\partial x}\left(\frac{M_{j}}{\rho_{j}}\right)
$$

and $\Delta x$ is the uncertainty in $x$. The $\Phi_{x}$ for Eq. (9) is obtained by differentiating Eq. (7) and are shown in Table 4.

\section{Experimental results}

\subsection{WSOC and inorganic composition}

Table 1 provides a summary of the composition for all samples analyzed in this study. The original $850 \mathrm{mg} \mathrm{C} \mathrm{L}^{-1} \mathrm{BB}$ sample had to be fractionated twice to yield enough carbon mass in samples for surface tension and KTA. The HPHOB, D-HPHIL, and D-HPHOB fractions shown in Table 1 are from this later fractionation. The desalted original sample contained significant amounts of ions after the desalting process (17\% of the original anion fraction) (Table 1) and thus is not considered in our analysis, as it does not truly reflect a "desalted" sample.

\subsection{Surface tension depression}

The WSOC of the original BB sample contains large amounts of surfactants; at a concentration of $850 \mathrm{mg} \mathrm{C} \mathrm{L}^{-1}$, $\sigma$ was measured to be $59 \mathrm{mN} \mathrm{m}^{-1}\left(25^{\circ} \mathrm{C}\right), 18 \%$ lower than

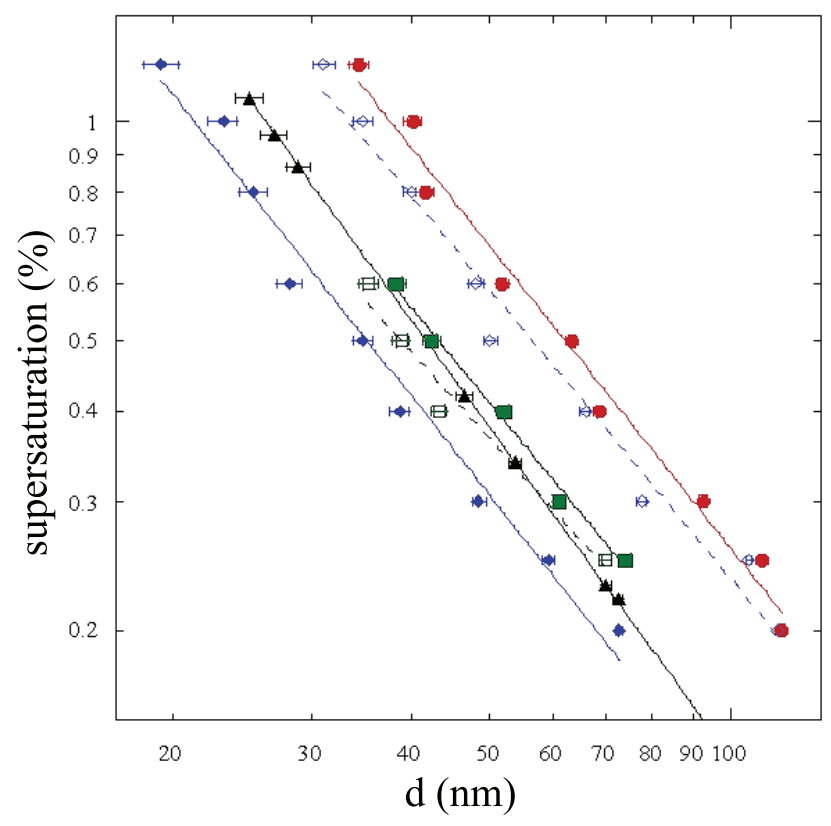

Fig. 6. Critical supersaturation vs. dry particle diameter for $\mathrm{BB}$ Fractions and $\left(\mathrm{NH}_{4}\right)_{2} \mathrm{SO}_{4}$. The original sample (solid red circles), hydrophobic (blue diamonds), hydrophilic (green squares) and $\left(\mathrm{NH}_{4}\right)_{2} \mathrm{SO}_{4}$ (black triangles) are shown. The desalted samples are represented by dashed lines and open symbols.

the surface tension at infinite dilution with 18-Mohm ultrapure water $\left(71.24 \pm 0.53 \mathrm{mN} \mathrm{m}^{-1}\right)$. The $\sigma$ value of the infinitely diluted solution is very close to pure water, $\sim 2 \%$ different from reported literature values for water at room temperature (Yaws, 1999). The $\sigma$ value for BB is similar in magnitude to the surface tension depression reported by Facchini et al. (2000) for fog water samples and Kiss et al. (2005) for HULIS dissolved in water.

From our speciated aerosol study, the original sample and hydrophobic component can significantly depress surface tension with increasing carbon concentration; the hydrophilic components do not (Fig. 4). The desalted hydrophobic and desalted hydrophilic components do not depress surface tension as much as their salted counterparts. Of the three salted samples, the HPHOB sample exhibits the largest sensitivity to the presence of salts. The behavior of the HPHOB fraction suggests it is composed of HULIS (Sullivan and Weber, 2006a). The D-HPHIL and HPHIL fractions effectively have the same $\sigma$ as water, even at very large carbon concentrations (Fig. 4).

Addition of electrolytes to the BB sample (where WSOC concentration is maintained constant at $850 \mathrm{mg} \mathrm{L}^{-1}$ ) further depresses droplet $\sigma$ (Fig. 5). This is consistent with behavior seen by Kiss et al. (2005) for HULIS with salts. Greater amounts of $\mathrm{NaCl}$ than $\left(\mathrm{NH}_{4}\right)_{2} \mathrm{SO}_{4}$ are required to reduce surface tension by the same amount, as the bivalent $\mathrm{SO}_{4}^{2-}$ is more effective than $\mathrm{Cl}^{-}$in partitioning the hydrophobic 
Table 4. Sensitivity of Molar Volume to its dependant parameters.

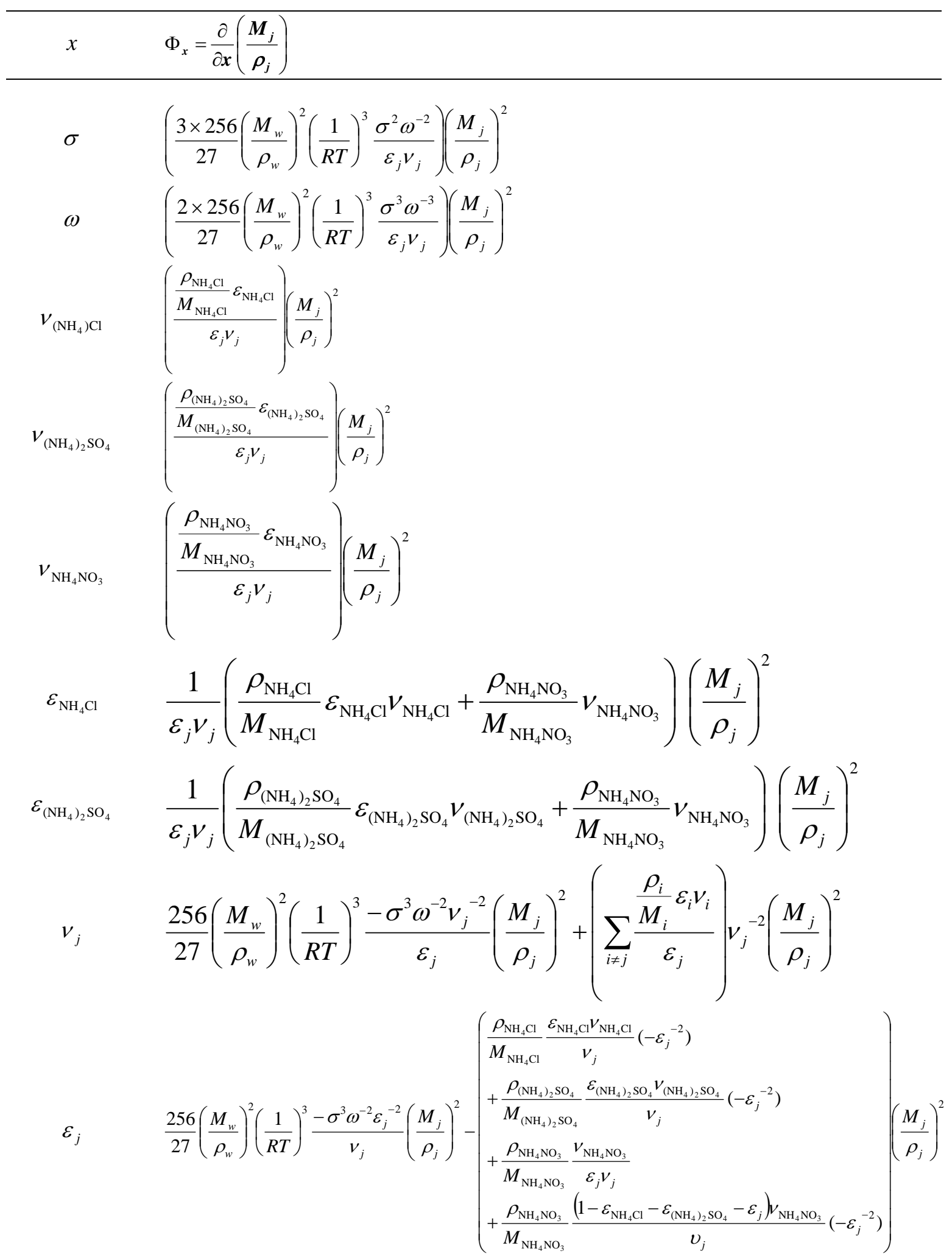


organics (which are anionic surfactants) to the surface layer (Holmberg, 2003; Hunter, 2001). Nonetheless, the increasing presence of an inorganic salt in the BB sample (which could happen e.g., in cloud processing of the aerosol) can further decrease surface tension by more than $20 \%$ and hence can have an important impact on CCN activity.

\subsection{CCN activity}

Figure 6 shows the critical supersaturation, $s_{c}$, of particles generated from the BB and fractionated samples, as a function of their $d$. $\left(\mathrm{NH}_{4}\right)_{2} \mathrm{SO}_{4}$ has been added as a basis of comparison, and from its van't Hoff factor and molar volume, is expected to be more $\mathrm{CCN}$ active than all samples of Table 1 (i.e., its activation spectrum should lie to the left of the samples). Indeed, this is mostly the case; the activation spectra for HPHIL and D-HPHIL are closest to $\left(\mathrm{NH}_{4}\right)_{2} \mathrm{SO}_{4}$. Strong surfactants are not present in the HPHIL, D-HPHIL, as their surface tension is not substantially different from water, even at very high carbon concentrations (Fig. 5). This suggests that the hydrophilic components are composed of soluble, low molecular weight compounds which is consistent with the functional group calibration analysis of Sullivan and Weber, (2006a; 2006b) done for similar samples.

Surprisingly, HPHOB (which contains the least hydrophilic components of WSOC) was the most CCN active of all samples, surpassing even $\left(\mathrm{NH}_{4}\right)_{2} \mathrm{SO}_{4}$ (Fig. 6). This seemingly counterintuitive finding can be reconciled when considering the synergism between the salts and organics. HPHOB contains large amounts of salts, so based on that alone, one would expect $\mathrm{CCN}$ activity close to pure $\left(\mathrm{NH}_{4}\right)_{2} \mathrm{SO}_{4}$. However, the surfactants present in HPHOB, because of the concentrated salts present in the $\mathrm{CCN}$, tend to partition on the $\mathrm{CCN}$ surface and depress surface tension, as was seen in Fig. 5. This "salting out" effect of the organics would then decrease the $\mathrm{CCN}$ critical supersaturation, making the HPHOB better $\mathrm{CCN}$ than pure $\left(\mathrm{NH}_{4}\right)_{2} \mathrm{SO}_{4}$. "Salting out" of organics can also explain why HPHOB becomes even more $\mathrm{CCN}$ active (compared to $\left.\left(\mathrm{NH}_{4}\right)_{2} \mathrm{SO}_{4}\right)$ as the dry $\mathrm{CCN}$ diameter decreases (Fig. 6); according to Köhler theory, the concentration of solute (organic and inorganic) increases at the point of activation as dry particle size decreases. Both decrease surface tension as dry size decreases, which implies that the CCN activity of HPHOB and $\left(\mathrm{NH}_{4}\right)_{2} \mathrm{SO}_{4}$ diverge more at small diameters. Conversely, at large $d$, the concentrations of solute at the point of activation are lower, the surface depression of HPHOB is relatively small, and the $\mathrm{CCN}$ activity curve of HPHOB and $\left(\mathrm{NH}_{4}\right)_{2} \mathrm{SO}_{4}$ tend to converge (Fig. 6).

The D-HPHOB fraction has lower $\mathrm{CCN}$ activity than $\left(\mathrm{NH}_{4}\right)_{2} \mathrm{SO}_{4}$ and HPHOB. In comparison to $\left(\mathrm{NH}_{4}\right)_{2} \mathrm{SO}_{4}$, lowering of surface tension in D-HPHOB is not compensated by the lack of solute during the desalting. D-HPHOB and BB have similarly low CCN activity and the BB sample is the least active of all samples. As illustrated in Fig. 6, one can-
Table 5. Results of Köhler Theory Analysis.

\begin{tabular}{lll}
\hline Sample & $\left(\frac{M_{j}}{\rho_{j}}\right)\left(\mathrm{m}^{3} \mathrm{~mol}^{-1}\right)$ & $\mathrm{M}_{j}^{\mathrm{e}}\left(\mathrm{g} \mathrm{mol}^{-1}\right)$ \\
\hline BB & $1.6 \times 10^{-4}$ & 248 \\
D-HPHIL & $6.2 \times 10^{-5}$ & 87 \\
D-HPHOB & $5.6 \times 10^{-4}\left(\operatorname{method} \mathbf{b}_{\mathbf{1}}\right)^{\mathrm{f}}$ & $780\left(\operatorname{method} \mathbf{b}_{\mathbf{1}}\right)^{\mathrm{f}}$ \\
& $6.1 \times 10^{-4}\left(\operatorname{method} \mathbf{b}_{\mathbf{2}}\right)$ & $859\left(\operatorname{method} \mathbf{b}_{\mathbf{2}}\right)$ \\
\hline
\end{tabular}

e Assuming an average density of $1400 \mathrm{~kg} \mathrm{~m}^{-3}$ (Turpin and Lim, 2001).

${ }^{\mathrm{f}}$ Determined from data with $s_{c}$ between $0.4 \%$ and $0.6 \%$.

not assume the CCN activity of BB should reside somewhere between HPHOB and HPHIL. Even though the BB sample contains more soluble material (mostly inorganics and some unknown amount of hydrophilics) and did depress surface tension (attributed the presence of electrolytes and hydrophobics) the contribution and interactions with water vapor of all three speciated components: hydrophilics, hydrophobics and inorganics is not additive. Regardless, KTA on all samples should give molar volume estimates that are consistent, i.e., lowest for HPHIL, then BB, and finally, HPHOB.

\section{Köhler theory analysis of samples}

\subsection{Molar volume estimations}

We compute average organic molar volumes for the original and desalted hydrophobic and hydrophilic samples (i.e., BB, D-HPHIL, D-HPHOB), where the organic volume fraction dominates (Table 5) hence KTA is subject to less uncertainty (Padró et al., 2007). The inorganic compounds present in the sample are assumed to be a mixture of ammonium sulfate, ammonium chloride, and ammonium nitrate in proportion to their ionic concentrations (Table 1).

In computing the volume fraction of each constituent in the dry aerosol, Eq. (4), we multiplied the WSOC concentration with 1.4 to obtain the total dissolved organic carbon mass concentration (Turpin and Lim, 2001); the relative amount of each component (OC and inorganic salts) in solution is then used to determine their mass fraction, $m_{i}$, in the dry aerosol (Table 1). The characteristics of our hydrophobic sample resemble the extracted F5 sample of Dinar et al. (2006a) which has a density of $1.5 \mathrm{~g} \mathrm{~cm}^{-3}$; to obtain a lower limit for molar mass, we apply KTA for the reported density between 1.4 to $1.6 \mathrm{~g} \mathrm{~cm}^{-3}$ (Dinar et al., 2006a; Turpin and Lim, 2001). In applying Eq. (4), the density of $\left(\mathrm{NH}_{4}\right)_{2} \mathrm{SO}_{4}, \mathrm{NH}_{4} \mathrm{Cl}, \mathrm{NH}_{4} \mathrm{NO}_{3}$ was taken to be 1760,1800 , and $1500 \mathrm{~kg} \mathrm{~m}^{-3}$, respectively (Perry et al., 1997). In the case of hydrophobic molar volume analysis, surface tension becomes negative when the Szyszkowski-Langmuir fit of our data is applied, implying that the asymptotic value for surface tension (equivalent to the "critical micelle concentration" for 
Table 6. Molar volume sensitivity analysis for BB sample.

\begin{tabular}{llll}
\hline $\begin{array}{l}\text { Property } x \\
\text { (units) }\end{array}$ & $\Delta x$ & $\begin{array}{l}\Phi_{x} \\
\left(\mathrm{~m}^{3} \mathrm{~mol}^{-1} x^{-1}\right)\end{array}$ & $\begin{array}{l}\text { Molar volume } \\
\text { uncertainty (\%) }\end{array}$ \\
\hline$\sigma\left(\mathrm{N} \mathrm{m}^{-1}\right)$ & $1.37 \times 10^{-3}$ & $1.063 \times 10^{-2}$ & 9.7 \\
$\omega\left(\mathrm{m}^{1.5}\right)$ & $9.49 \times 10^{-15}$ & $6.25 \times 10^{9}$ & 39.3 \\
$\nu_{\mathrm{NH}_{4} \mathrm{Cl}}$ & 0.5 & $1.49 \times 10^{-5}$ & 4.9 \\
$\nu_{\left(\mathrm{NH}_{4}\right)_{2} \mathrm{SO}_{4}}$ & 0.5 & $7.43 \times 10^{-6}$ & 2.5 \\
$\nu_{\mathrm{NH}_{4} \mathrm{NO}_{3}}$ & 0.5 & $6.08 \times 10^{-6}$ & 2.0 \\
$\varepsilon_{\mathrm{NH}_{4} \mathrm{Cl}}$ & $1.95 \times 10^{-3}$ & $9.34 \times 10^{-4}$ & 1.2 \\
$\varepsilon_{\left(\mathrm{NH}_{4}\right)_{2} \mathrm{SO}_{4}}$ & $2.03 \times 10^{-3}$ & $9.22 \times 10^{-4}$ & 1.2 \\
$\varepsilon_{\text {organic }}$ & $6.36 \times 10^{-3}$ & $1.09 \times 10^{-3}$ & 4.6 \\
$\nu_{\text {organic }}$ & $0.20^{\#}$ & $1.78 \times 10^{-4}$ & 23.6 \\
Total uncertainty & & & 47.5 \\
\hline
\end{tabular}

\# based on observations for HULIS; Dinar et al. (2006b).

Table 7. Molar volume sensitivity analysis for D-HPHIL sample.

\begin{tabular}{llll}
\hline $\begin{array}{l}\text { Property } x \\
\text { (units) }\end{array}$ & $\Delta x$ & $\begin{array}{l}\Phi_{x} \\
\left(\mathrm{~m}^{3} \mathrm{~mol}^{-1} x^{-1}\right)\end{array}$ & $\begin{array}{l}\text { Molar volume } \\
\text { uncertainty (\%) }\end{array}$ \\
\hline$\sigma\left(\mathrm{N} \mathrm{m}^{-1}\right)$ & $1.37 \times 10^{-3}$ & $3.90 \times 10^{-3}$ & 7.2 \\
$\omega\left(\mathrm{m}^{1.5}\right)$ & $4.43 \times 10^{-15}$ & $4.62 \times 10^{9}$ & 27.6 \\
$\nu_{\mathrm{NH}_{4} \mathrm{Cl}}$ & 0.5 & $3.58 \times 10^{-8}$ & 0.0 \\
$\nu_{\left(\mathrm{NH}_{4}\right)_{2} \mathrm{SO}_{4}}$ & 0.5 & $2.70 \times 10^{-9}$ & 0.0 \\
$\varepsilon_{\mathrm{NH}_{4} \mathrm{Cl}}$ & $6.89 \times 10^{-5}$ & $8.27 \times 10^{-5}$ & 0.0 \\
$\varepsilon_{\left(\mathrm{NH}_{4}\right)_{2} \mathrm{SO}_{4}}$ & $1.31 \times 10^{-5}$ & $8.26 \times 10^{-5}$ & 0.0 \\
$\varepsilon_{\text {organic }}$ & $8.2 \times 10^{-5}$ & $1.72 \times 10^{-4}$ & 0.0 \\
$\nu_{\text {organic }}$ & $0.20^{\#}$ & $3.56 \times 10^{-5}$ & 9.6 \\
Total uncertainty & & & 30.1 \\
\hline
\end{tabular}

${ }^{\#}$ based on observations for HULIS; Dinar et al. (2006b).

single-component aerosol) is reached at the point of activation. Because of this, the surface tension of hydrophobics is set to $50 \%$ of pure water, corresponding to the lower limit observed for HULIS (Kiss et al., 2005).

The effective van't Hoff factor, $v$, (defined as the number of ions released into the solution times the osmotic coefficient) expresses the impact of dissociation on water activity. For multicomponent electrolyte solutions, $v$ can be accurately computed with existing thermodynamic models (Nenes et al., 1998) and has been successfully applied for activation of inorganic CCN (e.g., Raymond and Pandis, 2002). However, in solutions of WSOC with electrolytes (which characterize all the samples of this study), $v$ is quite uncertain as speciation in solution is not known, and modeling complex organic-water-inorganic interactions is challenging. For this reason, we approximate $v$ as follows: $i$ ) $\nu=2$ for $\mathrm{NH}_{4} \mathrm{Cl}$ and $\left.\mathrm{NH}_{4} \mathrm{NO}_{3}, i i\right) \nu=3$ for $\left.\left(\mathrm{NH}_{4}\right)_{2} \mathrm{SO}_{4}, i i i\right) \nu=1$ for organics in the BB sample, as the sample is acidic and organics are not expected to substantially dissociate, $i v) \nu=1$ for organics in the HPHOB and D-HPHOB samples, as they are very weakly dissociating and iv) $v=2.5$ for D-HPHIL, as we assume the sample to be composed of dicarboxylic acids neutralized with ammonium during the extraction process; the
Table 8. Molar volume sensitivity analysis for D-HPHOB sample.

\begin{tabular}{llll}
\hline $\begin{array}{l}\text { Property } x \\
\text { (units) }\end{array}$ & $\Delta x$ & $\begin{array}{l}\Phi_{x} \\
\left(\mathrm{~m}^{3} \mathrm{~mol}^{-1} x^{-1}\right)\end{array}$ & $\begin{array}{l}\text { Molar volume } \\
\text { uncertainty }(\%)\end{array}$ \\
\hline$\sigma\left(\mathrm{N} \mathrm{m}^{-1}\right)$ & $7.06 \times 10^{-4}$ & $5.53 \times 10^{-2}$ & 7.0 \\
$\omega\left(\mathrm{m}^{1.5}\right)$ & $4.43 \times 10^{-15}$ & $2.08 \times 10^{10}$ & 16.5 \\
$\nu_{\mathrm{NH}} \mathrm{Cl}$ & 0.5 & $2.65 \times 10^{-7}$ & 0.0 \\
$\nu_{\left(\mathrm{NH}_{4}\right)_{2} \mathrm{SO}_{4}}$ & 0.5 & $3.38 \times 10^{-7}$ & 0.0 \\
$\varepsilon_{\mathrm{NH}_{4} \mathrm{Cl}}$ & $3.63 \times 10^{-6}$ & $1.16 \times 10^{-2}$ & 0.0 \\
$\varepsilon_{\left(\mathrm{NH}_{4}\right)_{2} \mathrm{SO}_{4}}$ & 0 & $1.16 \times 10^{-2}$ & 0.0 \\
$\varepsilon_{\text {organic }}$ & $1.16 \times 10^{-5}$ & $1.23 \times 10^{-2}$ & 0.0 \\
$v_{\text {organic }}$ & $0.20^{\#}$ & $6.50 \times 10^{-4}$ & 23.3 \\
Total uncertainty & & & 29.5 \\
\hline
\end{tabular}

\# based on observations for HULIS; Dinar et al. (2006b).

ammonium salts are then assumed to dissociate as effectively as $\left(\mathrm{NH}_{4}\right)_{2} \mathrm{SO}_{4}$. The uncertainty in organic van't hoff factor can be as large as $20 \%$ (as titration experiments suggest; Dinar et al. 2006b) and is considered in our sensitivity analysis.

The molar volumes of the organic aerosol components are estimated employing KTA (presented in Sect. 2) and the above effective van't Hoff assumptions, the results of which are shown in Table 5. The molar volume of the hydrophilic organic $\left(6.2 \times 10^{-5} \mathrm{~m}^{3} \mathrm{~mol}^{-1}\right)$ is comparable to that of inorganic salts $\left(7.46 \times 10^{-5} \mathrm{~m}^{3} \mathrm{~mol}^{-1}\right.$ and $2.97 \times 10^{-5} \mathrm{~m}^{3} \mathrm{~mol}^{-1}$ for $\left(\mathrm{NH}_{4}\right)_{2} \mathrm{SO}_{4}$ and $\left(\mathrm{NH}_{4}\right) \mathrm{Cl}$, respectively) and low molecular weight mono- and di-carboxylic chains (e.g., formic and acetic acid, and succinic, glutaric, and oxalic acid with $7.54 \times 10^{-5} \mathrm{~m}^{3} \mathrm{~mol}^{-1}, 9.34 \times 10^{-5} \mathrm{~m}^{3} \mathrm{~mol}^{-1}$, and $6.4 \times 10^{-5} \mathrm{~m}^{3} \mathrm{~mol}^{-1}$, respectively) typical of those identified in the XAD- 8 calibration studies (Sullivan and Weber, 2006a). The significantly larger estimated molar volume of the hydrophobic fraction $\left(5.6 \times 10^{-4} \mathrm{~m}^{3} \mathrm{~mol}^{-1}\right.$ using method $\left.\mathbf{b}_{1}\right), 6.1 \times 10^{-4} \mathrm{~m}^{3} \mathrm{~mol}^{-1}$ using method $\mathbf{b}_{2}$ ) is consistent with the existence of HULIS in the sample which has has been previously shown by mass spectrometery methods to have molecular weights up to 1000 amu (Graber and Rudich, 2006). Nevertheless, we speculate that the average organic molar mass inferred from KTA could be smaller for several reasons: $i$ ) the KTA value is a number averaged property, which weighs the average towards a smaller number, when compared to mass-based averaging and ii) HULIS may have a higher $v$ than unity, as they are comprised of several polyfunctional groups that may contain polar groups like carbonyls, carboxyls, and hydroxls (Graber and Rudich, 2006; Kiss et al., 2002). Therefore, when KTA is applied assuming $\nu=1$, the inferred molar volume decreases to compensate.

The average molar mass for the original BB samples was found to be $248 \mathrm{~g} \mathrm{~mol}^{-1}$. Assuming that the organics in the original BB sample is a mixture of D-HPHIL and D-HPOB, we can infer the relative proportion of HPHIL and HPOB via the following equation

$M_{B B}=\chi M_{\mathrm{HPHIL}}+(1-\chi) M_{\mathrm{HPHOB}}$ 
Table 9. Molar volume sensitivity analysis for D-HPHOB at each supersaturation measured.

\begin{tabular}{|c|c|c|c|c|c|c|c|}
\hline Quantity (units) & $s=1.00 \%$ & $0.80 \%$ & $0.60 \%$ & $0.50 \%$ & $0.40 \%$ & $0.30 \%$ & $0.20 \%$ \\
\hline$\left(\frac{M_{j}}{\rho_{j}}\right)\left(\mathrm{m}^{3} \mathrm{~mol}^{-1}\right)$ & $5.97 \times 10^{-4}$ & $5.80 \times 10^{-4}$ & $5.57 \times 10^{-4}$ & $4.45 \times 10^{-4}$ & $6.51 \times 10^{-4}$ & $5.98 \times 10^{-4}$ & $8.68 \times 10^{-4}$ \\
\hline$\sigma\left(\mathrm{N} \mathrm{m}^{-1}\right)$ & $3.53 \times 10^{-2}$ & $3.53 \times 10^{-2}$ & $3.53 \times 10^{-2}$ & $3.53 \times 10^{-2}$ & $3.53 \times 10^{-2}$ & $3.53 \times 10^{-2}$ & $3.53 \times 10^{-2}$ \\
\hline$\Delta \sigma$ & $7.06 \times 10^{-4}$ & $7.06 \times 10^{-4}$ & $7.06 \times 10^{-4}$ & $7.06 \times 10^{-4}$ & $7.06 \times 10^{-4}$ & $7.06 \times 10^{-4}$ & $7.06 \times 10^{-4}$ \\
\hline$\Phi_{\sigma}\left(\mathrm{m}^{4} \mathrm{~mol}^{-1} \mathrm{~N}^{-1}\right)$ & $5.93 \times 10^{-2}$ & $5.76 \times 10^{-2}$ & $5.42 \times 10^{-2}$ & $4.43 \times 10^{-2}$ & $6.47 \times 10^{-2}$ & $5.96 \times 10^{-2}$ & $8.65 \times 10^{-2}$ \\
\hline$\Phi_{\sigma} \Delta_{\sigma}$ & $7.01 \%$ & $7.02 \%$ & $6.87 \%$ & $7.02 \%$ & $7.02 \%$ & $7.03 \%$ & $7.03 \%$ \\
\hline$\omega\left(\mathrm{m}^{1.5}\right)$ & $6.48 \times 10^{-14}$ & $6.39 \times 10^{-14}$ & $6.32 \times 10^{-14}$ & $5.60 \times 10^{-14}$ & $6.77 \times 10^{-14}$ & $6.48 \times 10^{-14}$ & $7.81 \times 10^{-14}$ \\
\hline$\Delta_{\omega}$ & $4.43 \times 10^{-15}$ & $4.43 \times 10^{-15}$ & $4.43 \times 10^{-15}$ & $4.43 \times 10^{-15}$ & $4.43 \times 10^{-15}$ & $4.43 \times 10^{-15}$ & $4.43 \times 10^{-15}$ \\
\hline$\Phi_{\omega}$ & $2.15 \times 10^{10}$ & $2.12 \times 10^{10}$ & $2.02 \times 10^{10}$ & $1.86 \times 10^{10}$ & $2.25 \times 10^{10}$ & $2.16 \times 10^{10}$ & $2.60 \times 10^{10}$ \\
\hline$\Phi_{\omega} \Delta \omega$ & $15.96 \%$ & $16.21 \%$ & $16.04 \%$ & $18.50 \%$ & $15.31 \%$ & $16.00 \%$ & $13.28 \%$ \\
\hline$\varepsilon_{\text {organic }}$ & 1.00 & 1.00 & 1.00 & 1.00 & 1.00 & 1.00 & 1.00 \\
\hline$\Delta \varepsilon_{\text {organic }}$ & $8.47 \times 10^{-4}$ & $8.47 \times 10^{-4}$ & $8.47 \times 10^{-4}$ & $8.47 \times 10^{-4}$ & $8.47 \times 10^{-4}$ & $8.47 \times 10^{-4}$ & $8.03 \times 10^{-19}$ \\
\hline$\Phi_{\varepsilon \text { organic }}\left(\mathrm{m}^{3} \mathrm{~mol}^{-1}\right)$ & 0 & $1.33 \times 10^{-2}$ & $1.22 \times 10^{-2}$ & $7.83 \times 10^{-3}$ & $1.70 \times 10^{-2}$ & $1.41 \times 10^{-2}$ & $2.91 \times 10^{-2}$ \\
\hline$\Phi_{\varepsilon \text { organic }} \Delta \varepsilon_{\text {organic }}$ & $0.00 \%$ & $1.94 \%$ & $1.86 \%$ & $1.49 \%$ & $2.21 \%$ & $1.99 \%$ & $0.00 \%$ \\
\hline$v_{\text {organic }}$ & 1.00 & 1.00 & 1.00 & 1.00 & 1.00 & 1.00 & 1.00 \\
\hline$\Delta v_{\text {organic }} \#$ & 0.2 & 0.2 & 0.2 & 0.2 & 0.2 & 0.2 & 0.2 \\
\hline$\Phi_{\nu \text { organic }}\left(\mathrm{m}^{3} \mathrm{~mol}^{-1}\right)$ & 0 & $6.57 \times 10^{-4}$ & $6.24 \times 10^{-4}$ & $4.07 \times 10^{-4}$ & $1.11 \times 10^{-3}$ & $6.41 \times 10^{-4}$ & $8.35 \times 10^{-4}$ \\
\hline$\Phi_{\nu \text { organic }} \Delta v_{\text {organic }}$ & $0.00 \%$ & $22.65 \%$ & $22.40 \%$ & $18.27 \%$ & $34.14 \%$ & $21.44 \%$ & $19.23 \%$ \\
\hline
\end{tabular}

\# based on observations for HULIS; Dinar et al. (2006b).

where $\chi$ is the mol fraction of hydrophilics in the original BB sample and $M_{B B}, M_{\mathrm{HPHIL}}, M_{\mathrm{HPHOB}}$ are the inferred molar masses from the BB, HPHIL and HPHOB samples. Equation 10 can be solved for $\chi$ to yield

$\chi=\left(\frac{M_{B B}-M_{\mathrm{HPHIL}}}{M_{\mathrm{HPHOB}}-M_{\mathrm{HPHIL}}}\right)$

We determine that $\chi \sim 0.25$, i.e., there are approximately 3 hydrophilic compounds for every 1 hydrophobic macromolecule in the original WSOC mixture.

\subsection{Molar volume sensitivity and uncertainty analysis}

Application of the sensitivity analysis requires quantification of the uncertainty for all parameters that affect $\left(\frac{M_{j}}{\rho_{j}}\right) . \Delta \sigma / \sigma$ is $2 \%$ (Sect. 4.2), $\Delta \omega$ is the standard deviation derived from the fit of $s$ and $d$ experimental data to the Köhler curve, $\Delta v_{i}$ is $0.5, \Delta v_{j}$ is 0.2 , and $\Delta \varepsilon_{i}$ and $\Delta \varepsilon_{j}$ are uncertainties associated with assuming organic aerosol density of 1.4 to $1.6 \mathrm{~g} \mathrm{~mol}^{-1}$ (Turpin and Lim, 2001).

The sensitivity analysis for methods $b_{1}$ and $b_{2}$ suggests that one of the largest sources of uncertainty for molar volume estimates arises from $\omega$ (Tables 6, 7, 8 and 9), which is not surprising, given that it cumulatively expresses CCN activity. Furthermore, $\omega$ may vary significantly in the presence of strong surfactants, as the concentration of solute at the critical diameter (which varies considerably over a range of $s_{c}$ ) controls $\sigma$. CCN with low $\mathrm{s}_{c}$ (large $d$ ) tend to have low WSOC concentration at activation and do not affect $\sigma$ depression at the droplet layer as much as CCN of smaller $d$ and higher $s_{c}$. For these reasons, $\sigma$ may contribute considerable uncertainty in organic molar volume estimates (up to $10 \%$ as shown) but can be the second largest source of uncertainty for samples containing strong surfactants (e.g., hydrophobics). In the case of hydrophobics, uncertainty from exact knowledge of $\sigma$ may introduce even larger uncertainty in molar volume estimates. The uncertainty in the van't Hoff factor may also be an important source of uncertainty in estimated organic molar volume ( $24 \%$ ) even though inorganic fractions and uncertainties are small (especially for the BB and D-HPHOB samples).

Using an average organic mass density of $1.4 \mathrm{~g} \mathrm{~cm}^{-3}$ (Turpin and Lim, 2001) we find the organic component in the original sample (BB) to have an average molar mass of $248 \pm 117 \mathrm{~g} \mathrm{~mol}^{-1}$, the hydrophobics in D-HPHOB to be on average $780 \pm 231 \mathrm{~g} \mathrm{~mol}^{-1}$ and the hydrophilic component of D-HPHIL to be the lightest, with an average of $87 \pm 26 \mathrm{~g} \mathrm{~mol}^{-1}$ (Table 5).

\section{Implications and summary}

This study is focused on characterizing the properties of water-soluble organics found in fresh biomass burning aerosol. The aerosol, after collection upon filters, is dissolved in water and fractionated into hydrophobic and hydrophilic components using XAD-8 solid phase extraction, and subsequently desalted. The original, fractionated and 
desalted samples are then characterized for their surfactant properties and average thermodynamic properties relevant for $\mathrm{CCN}$ activation (i.e., surface tension depression, solubility and average molar volume). Characterization of solubility and molar volume is done by combining $\mathrm{CCN}$ activity measurements with Köhler Theory using the method of "Köhler Theory Analysis" (KTA) (first introduced by Padró et al. (2007), and further developed here). The surface tension and CCN activity of these different samples are measured with a KSV CAM 200 goniometer and a DMT Streamwise Thermal Gradient CCN Counter, respectively.

It was found that the less hygroscopic soluble hydrophobic fractions can readily activate at high supersaturations and depending on the presence of inorganic species, can exhibit larger $\mathrm{CCN}$ activity than pure $\left(\mathrm{NH}_{4}\right)_{2} \mathrm{SO}_{4}$. This phenomenon can be attributed to "salting-out" of organics to the CCN surface layer from the presence of electrolytes; this would decrease surface tension and critical supersaturation. This hypothesis is supported by direct measurements of surface tension, as well as from measurements of $\mathrm{CCN}$ activity.

Surfactant behavior in the samples is attributed to the hydrophobic fraction that exhibit properties common to HULIS. The presence of inorganic salts may enhance surface tension depression to an extent in which insoluble hydrophobic aerosol may be better $\mathrm{CCN}$ than their pure inorganic counterparts. This supports the suggestion by Kiss et al. (2005), to include the interaction of inorganic and organic species effect on surface tension, whenever appropriate, in aerosol-cloud interaction studies and is consistent with the recent work of Ziese et al. (2007), who observed non-ideal CCN activity behaviour for HULIS extracted from aerosol samples.

Using an average organic mass density of $1.4 \mathrm{~g} \mathrm{~cm}^{-3}$ we infer the hydrophobic and hydrophilic fractions to be $780 \pm 231 \mathrm{~g} \mathrm{~mol}^{-1}$ and $87 \pm 26 \mathrm{~g} \mathrm{~mol}^{-1}$, respectively. From these average values, we estimate the relative molar ratio of hydrophilics to hydrophobics to be 3:1. Solubility limits, seen as an abrupt change in the scale dependence of $s_{c}$ from $d^{-1.5}$ to $d^{-a}(a>1.5)$, were not observed (Padró et al., 2007).

The inferred molar volumes for the samples considered in this study are on average subject to $36 \%$ uncertainty. Most of the uncertainty arises from the slope of the $s_{c}-d$ fit and $\sigma$ (Padró et al., 2007), and $v$ in the case of aggregate organics. Nevertheless, the molar volume estimates are in agreement with expected ranges for these compounds and suggest that KTA can be applied effectively to characterize $\mathrm{CCN}$ activity of water-soluble organic aerosol.

The study shown here presents a novel method to describe the complex detailed inorganic, organic and water vapor interactions within a Köhler theory framework appropriate for GCM parameterizations of aerosol-cloud interactions. We have demonstrated that this novel method can successfully be applied to a very complex aerosol and provide aggregate properties that comprehensively characterize its
$\mathrm{CCN}$ activity. In future work, the properties from other sources of carbonaceous aerosol should be characterized as presented here. Over time, such efforts will provide a comprehensive set of constraints for physically-based assessments of the indirect effects of carbonaceous aerosol.

Edited by: M. Ammann

\section{References}

Andreae, M. O. and Crutzen, P. J.: Atmospheric aerosols: Biogeochemical sources and role in atmospheric chemistry, Science, 276, 1052-1058, 1997.

Asa-Awuku, A., and Nenes, A.: Effect of solute dissolution kinetics on cloud droplet formation: Extended Köhler theory, J. Geophys. Res., 112, D22201, doi:10.1029/2005JD006934, 2007.

Asa-Awuku, A., Nenes, A., Gao, S., Flagan, R. C., and Seinfeld, J. H.: Alkene ozonolysis SOA: inferences on composition, CCN and growth kinetics from Köhler theory analysis, Atmos. Chem. Phys. Disscuss., 7, 3, 8983-9011, 2007.

Baumann, K., Ift, F., Zhao, J. Z., and Chameides, W. L.: Discrete measurements of reactive gases and fine particle mass and composition during the 1999 Atlanta Supersite Experiment, J. Geophys. Res., 108, 8416, doi:10.1029/2001JD001210, 2003.

Cachier, H., Liousse, C., Buatmenard, P., and Gaudichet, A.: Particulate Content of Savanna Fire Emissions, J. Atmos. Chem., 22, 123-148, 1995.

Cruz, C. N. and Pandis, S. N.: Deliquescence and hygroscopic growth of mixed inorganic-organic atmospheric aerosol, Env. Sci. Tech., 34, 4313-4319, 2000.

Decesari, S.: Source attribution of water-soluble organic aerosol by nuclear magnetic resonance spectroscopy, Env. Sci. Tech., 41, 2479-2484, 2007.

Decesari, S., Facchini, M. C., Fuzzi, S., and Tagliavini, E.: Characterization of water-soluble organic compounds in atmospheric aerosol: A new approach, J. Geophys. Res., 105, 1481-1489, doi:10.1029/1999JD900950, 2000.

Decesari, S., Facchini, M. C., Mircea, M., Cavalli, F., and Fuzzi, S.: Solubility properties of surfactants in atmospheric aerosol and cloud/fog water samples, J. Geophys. Res., 108, 4685, doi:10.1029/2003JD003566, 2003.

Dinar, E., Mentel, T. F., and Rudich, Y.: The density of humic acids and humic like substances (HULIS) from fresh and aged wood burning and pollution aerosol particles, Atmos. Chem. Phys., 6, 5213-5224, 2006a.

Dinar, E., Riziq, A. A., Spindler, C., Erlick, C., Kiss, G., and Rudich, Y.: The complex refractive index of atmospheric and model humic-like substances (HULIS) retrieved by a cavity ring down aerosol spectrometer (CRD-AS), Faraday Discuss., 137, 279-295, 2008.

Dinar, E., Taraniuk, I., Graber, E. R., Anttila, T., Mentel, T. F., and Rudich, Y.: Hygroscopic growth of atmospheric and model humic-like substances, J. Geophys. Res., 112, D05211, doi:10.1029/2006JD007442, 2007.

Dinar, E., Taraniuk, I., Graber, E. R., Katsman, S., Moise, T., Anttila, T., Mentel, T. F., and Rudich, Y.: Cloud Condensation Nuclei properties of model and atmospheric HULIS, Atmos. Chem. Phys., 6, 2465-2481, 2006b. 
Duarte, R. and Duarte, A. C.: Application of non-ionic solid sorbents (XAD resins) for the isolation and fractionation of watersoluble organic compounds from atmospheric aerosols, J. Atmos. Chem., 51, 79-93, 2005.

Facchini, M. C., Decesari, S., Mircea, M., Fuzzi, S., and Loglio, G.: Surface tension of atmospheric wet aerosol and cloud/fog droplets in relation to their organic carbon content and chemical composition, Atmos. Environ., 34, 4853-4857, 2000.

Facchini, M. C., Fuzzi, S., Zappoli, S., Andracchio, A., Gelencser, A., Kiss, G., Krivacsy, Z., Meszaros, E., Hansson, H. C., Alsberg, T., and Zebuhr, Y.: Partitioning of the organic aerosol component between fog droplets and interstitial air, J. Geophys. Res., 104, 26 821-26 832, doi:10.1029/1999JD900349, 1999a.

Facchini, M. C., Mircea, M., Fuzzi, S., and Charlson, R. J.: Cloud albedo enhancement by surface-active organic solutes in growing droplets, Nature 401, 257-259, 1999b.

Falkovich, A. H., Graber, E. R., Schkolnik, G., Rudich, Y., Maenhaut, W., and Artaxo, P.: Low molecular weight organic acids in aerosol particles from Rondonia, Brazil, during the biomassburning, transition and wet periods, Atmos. Chem. Phys., 5, 781797, 2005,

http://www.atmos-chem-phys.net/5/781/2005/.

Feingold, G. and Chuang, P. Y.: Analysis of the Influence of FilmForming Compounds on droplet Growth: Implications for Cloud Microphysical Processes and Climate, J. Atmos. Sci., 59, 20062018, 2002.

IPCC: Summary for Policymakers, in: Climate Change 2007: The Physical Science Basis. Contribution of Working Group I to the Fourth Assessment Report of the Intergovernmental Panel on Climate Change ,edited by: Solomon, S., Qin, D., Manning, M., Chen,,Z., Marquis, M., Averyt, K. B., Tignor, M., and Miller, H. L., Cambridge University Press, Cambridge, United Kingdom and New York, NY, USA, 2007.

Gill, P. S., Graedel, T. E., and Weschler, C. J.: Organic Films On Atmospheric Aerosol-Particles, Fog Droplets, Cloud Droplets, Raindrops, and Snowflakes, Rev. Geophys., 21, 903-920, 1983.

Graber, E. R. and Rudich, Y.: Atmospheric HULIS: How humiclike are they? A comprehensive and critical review, Atmos. Chem. Phys., 6, 729-753, 2006,

http://www.atmos-chem-phys.net/6/729/2006/.

Graham, B., Mayol-Bracero, O. L., Guyon, P., Roberts, G. C., Decesari, S., Facchini, M. C., Artaxo, P., Maenhaut, W., Koll, P., and Andreae, M. O.: Water-soluble organic compounds in biomass burning aerosols over Amazonia - 1. Characterization by NMR and GC-MS, J. Geophys. Res., 107, 8047, doi:8010.1029/2001JD000336, 2002.

Gysel, M., Weingartner, E., Nyeki, S., Paulsen, D., Baltensperger, U., Galambos, I., and Kiss, G.: Hygroscopic properties of water-soluble matter and humic-like organics in atmospheric fine aerosol, Atmos. Chem. Phys., 4, 35-50, 2004, http://www.atmos-chem-phys.net/4/35/2004/.

Havers, N., Burba, P., Lambert, J., and Klockow, D.: Spectroscopic characterization of humic-like substances in airborne particulate matter, J. Atmos. Chem., 29, 45-54, 1998.

Holmberg, K.: 1946- Surfactants and polymers in aqueous solution, John Wiley \& Sons, Chichester, West Sussex, England; Hoboken, NJ, 2003.

Hunter, R. J.: Foundations of colloid science, Oxford University Press, Oxford; New York, 806 pp., 2001.
Kalberer, M.: Analysis of oligomers in atmospheric aerosol particles - analytical challenges, Anal. Bioanal. Chem., 385, 22-25, 2006.

Kalberer, M., Paulsen, D., Sax, M., Steinbacher, M., Dommen, J., Prevot, A. S. H., Fisseha, R., Weingartner, E., Frankevich, V., Zenobi, R., and Baltensperger, U.: Identification of polymers as major components of atmospheric organic aerosols, Science, 303, 1659-1662, doi:10.1126/science.1092185, 2004.

Kanakidou, M., Seinfeld, J. H., Pandis, S. N., Barnes, I., Dentener, F. J., Facchini, M. C., Van Dingenen, R., Ervens, B., Nenes, A., Nielsen, C. J., Swietlicki, E., Putaud, J. P., Balkanski, Y., Fuzzi, S., Horth, J., Moortgat, G. K., Winterhalter, R., Myhre, C. E. L., Tsigaridis, K., Vignati, E., Stephanou, E. G., and Wilson, J.: Organic aerosol and global climate modelling: a review, Atmos. Chem. Phys., 5, 1053-1123, 2005,

http://www.atmos-chem-phys.net/5/1053/2005/.

Kiss, G., Tombacz, E., and Hansson, H. C.: Surface tension effects of humic-like substances in the aqueous extract of tropospheric fine aerosol, J. Atmos. Chem., 50, 279-294, doi:10.1007/s10874-005-5079-5, 2005.

Kiss, G., Tombacz, E., Varga, B., Alsberg, T., and Persson, L.: Estimation of the average molecular weight of humic-like substances isolated from fine atmospheric aerosol, Atmos. Environ., 37, 3783-3794, doi:10.1029/2001/JD000603, 2003.

Kiss, G., Varga, B., Galambos, I., and Ganszky, I.: Characterization of water-soluble organic matter isolated from atmospheric fine aerosol, J. Geophys. Res., 107, 8339, doi:10.1016/j.atmosenv.2003.10.049, 2002.

Kiss, G., Varga, B., Gelencser, A., Krivacsy, Z., Molnar, A., Alsberg, T., Persson, L., Hansson, H. C., and Facchini, M. C.: Characterisation of polar organic compounds in fog water, Atmos. Environ., 35, 2193-2200, 2001.

Köhler, H.: The nucleus in and the growth of hygroscopic droplets, Transactions of the Faraday Society, 43, 1152-1161, 1936.

Krivacsy, Z., Gelencser, A., Kiss, G., Meszaros, E., Molnar, A., Hoffer, A., Meszaros, T., Sarvari, Z., Temesi, D., Varga, B., Baltensperger, U., Nyeki, S., and Weingartner, E.: Study on the chemical character of water soluble organic compounds in fine atmospheric aerosol at the Jungfraujoch, J. Atmos. Chem., 39, 235-259, 2001.

Krivacsy, Z., Kiss, G., Varga, B., Galambos, I., Sarvari, Z., Gelencser, A., Molnar, A., Fuzzi, S., Facchini, M. C., Zappoli, S., Andracchio, A., Alsberg, T., Hansson, H. C., and Persson, L.: Study of humic-like substances in fog and interstitial aerosol by size-exclusion chromatography and capillary electrophoresis, Atmos. Environ., 34, 4273-4281, 2000.

Lance, S., Medina, J., Smith, J. N., and Nenes, A.: Mapping the operation of the DMT Continuous Flow CCN counter, Aerosol Sci. Tech., 40, 242-254, 2006.

Lance, S., Nenes, A., and Rissman, T. A.: Chemical and dynamical effects on cloud droplet number: Implications for estimates of the aerosol indirect effect, J. Geophys. Res., 109, doi:10.1029/2004JD004596, 2004.

Langmuir, I.: The constitution and fundamental properties of solids and liquids. II. Liquids, J. Am. Chem. Soc., 39, 1848-1906, 1917.

Lee, S., Baumann, K., Schauer, J. J., Sheesley, R. J., Naeher, L. P., Meinardi, S., Blake, D. R., Edgerton, E. S., Russell, A. G., and Clements, M.: Gaseous and particulate emissions from 
prescribed burning in Georgia, Env. Sci. Tech., 39, 9049-9056, 2005.

Limbeck, A., Kulmala, M., and Puxbaum, H.: Secondary organic aerosol formation in the atmosphere via heterogeneous reaction of gaseous isoprene on acidic particles, Geophys. Res. Lett., 30, 1996, doi:10.1029/2003GL017738,, 2003.

Mayol-Bracero, O. L., Guyon, P., Graham, B., Roberts, G., Andreae, M. O., Decesari, S., Facchini, M. C., Fuzzi, S., and Artaxo, P.: Water-soluble organic compounds in biomass burning aerosols over Amazonia - 2. Apportionment of the chemical composition and importance of the polyacidic fraction, J. Geophys. Res., 107, 8091, doi:10.1029/2001JD000522, 2002.

Nenes, A., Charlson, R. J., Facchini, M. C., Kulmala, M., Laaksonen, A., and Seinfeld, J. H.: Can chemical effects on cloud droplet number rival the first indirect effect?, Geophys. Res. Lett., 29, 1848, doi:10.1029/2002GL015295, 2002.

Nenes, A., Pandis, S. N., and Pilinis, C.: ISORROPIA: A new thermodynamic equilibrium model for multiphase multicomponent inorganic aerosols, Aqua. Geochem., 4, 123-152, 1998.

Padró, L. T., Asa-Awuku, A., Morisson, R., and Nenes, A.: Inferring Thermodynamic Properties from CCN Activation Experiments a) Single-component and Binary Aerosols, Atmos. Chem. Phys., 7, 5263-5274, 2007,

http://www.atmos-chem-phys.net/7/5263/2007/.

Perry, R. H., Green, D. W., and Maloney, J. O.: Perry's Chemical Engineers' Handbook., McGraw-Hill, New York, 1997.

Petters, M. D., and Kreidenweis, S. M.: A single parameter representation of hygroscopic growth and cloud condensation nucleus activity, Atmos. Chem. Phys., 7, 1961-1971, 2007, http://www.atmos-chem-phys.net/7/1961/2007/.

Raymond, T. R., and Pandis, S. N.: Cloud activation of singlecomponent organic aerosol particles, J. Geophys. Res., 107, 4787, doi:10.1029/2002JD002159, 2002

Rissler, J., Vestin, A., Swietlicki, E., Fisch, G., Zhou, J., Artaxo, P., and Andreae, M. O.: Size distribution and hygroscopic properties of aerosol particles from dry-season biomass burning in Amazonia, Atmos. Chem. Phys., 6, 471-491, 2006 , http://www.atmos-chem-phys.net/6/471/2006/.

Roberts, G. C., and Nenes, A.: A continuous-flow streamwise thermal-gradient $\mathrm{CCN}$ chamber for atmospheric measurements, Aerosol Sci. Tech., 39, 206-221, 2005.

Salma, I., Ocskay, R., Varga, I., and Maenhaut, W.: Surface tension of atmospheric humic-like substances in connection with relaxation, dilution, and solution pH, J. Geophys. Res., 111, D23205, doi:10.1029/2005JD007015, 2006.

Samburova, V., Zenobi, R., and Kalberer, M.: Characterization of high molecular weight compounds in urban atmospheric particles, Atmos. Chem. Phys., 5, 2163-2170, 2005, http://www.atmos-chem-phys.net/5/2163/2005/.

Sannigrahi, P., Sullivan, A. P., Weber, R. J., and Ingall, E. D.: Characterization of water-soluble organic carbon in urban atmospheric aerosols using solid-state C-13 NMR spectroscopy, Env. Sci. Tech., 40, 666-672, 2006.

Seinfeld, J. H. and Pandis, S. N.: Atmospheric Chemistry and Physics: From Air Pollution to Climate Change, John Wiley \& Sons, 1326 pp., 1998.
Shulman, M. L., Jacobson, M. C., Carlson, R. J., Synovec, R. E., and Young, T. E.: Dissolution behavior and surface tension effects of organic compounds in nucleating cloud droplets, Geophys. Res. Lett., 23, 277-280, doi:10.1029/95GL03810, 1996.

Sullivan, A. P., Peltier, R. E., Brock, C. A., de Gouw, J. A., Holloway, J. S., Warneke, C., Wollny, A. G., and Weber, R. J.: Airborne measurements of carbonaceous aerosol soluble in water over northeastern United States: Method development and an investigation into water-soluble organic carbon sources, J. Geophys. Res., 111, D23S46, doi:10.1029/2006JD007072, 2006.

Sullivan, A. P. and Weber, R. J.: Chemical characterization of the ambient organic aerosol soluble in water: 1 . Isolation of hydrophobic and hydrophilic fractions with a XAD-8 resin, J. Geophys. Res., 111, D05314, doi:10.1029/2005JD006485, 2006 a.

Sullivan, A. P. and Weber, R. J.: Chemical characterization of the ambient organic aerosol soluble in water: 2. Isolation of acid, neutral, and basic fractions by modified sizeexclusion chromatography, J. Geophys. Res., 111, D05315, doi:10.1029/2005JD006486, 2006b.

Sullivan, A. P., Weber, R. J., Clements, A. L., Turner, J. R., Bae, M. S., and Schauer, J. J.: A method for on-line measurement of water-soluble organic carbon in ambient aerosol particles: Results from an urban site, Geophys. Res. Lett., 31, L13105, doi:10.1029/2004GL019681, 2004.

Taraniuk, I., Graber, E. R., Kostinski, A., and Rudich, Y.: Surfactant properties of atmospheric and model humiclike substances (HULIS), Geophys. Res. Lett., 34, L16807, doi:10.1029/2007GL029576, 2007.

Turpin, B. J. and Lim, H. J.: Species contributions to $\mathrm{PM}_{2} .5$ mass concentrations: Revisiting common assumptions for estimating organic mass, Aerosol Sci. Tech., 35, 602-610, 2001.

Wex, H., Hennig, T., Salma, I., Ocskay, R., Kiselev, A., Henning, S., Massling, A., Wiedensohler, A., and Stratmann, F.: Hygroscopic growth and measured and modeled critical super-saturations of an atmospheric HULIS sample, Geophys. Res. Lett., 34, 2007.

Yamasoe, M. A., Artaxo, P., Miguel, A. H., and Allen, A. G.: Chemical composition of aerosol particles from direct emissions of vegetation fires in the Amazon Basin: water-soluble species and trace elements, Atmos. Environ., 34, 1641-1653, 2000.

Yaws, C. L.: Chemical properties handbook: physical, thermodynamic, environmental, transport, safety, and health related properties for organic and inorganic chemicals, C. L. Yaws., edited, pp. vii, 779 p., ill.; 729 cm, McGraw-Hill, New York, 1999.

Zappoli, S., Andracchio, A., Fuzzi, S., Facchini, M. C., Gelencser, A., Kiss, G., Krivacsy, Z., Molnar, A., Meszaros, E., Hansson, H. C., Rosman, K., and Zebuhr, Y.: Inorganic, organic and macromolecular components of fine aerosol in different areas of Europe in relation to their water solubility, Atmos. Environ., 33, 2733 2743, 1999.

Ziese, M., Wex, H., Nilsson, E., Salma, I., Ocksay, R., Henning, T., Massling, A., and Stratmann, F.: Hygroscopic growth and activation of HULIS particles: experimental data and a new iterative parameterization scheme for complex aerosol particles, Atmos. Chem. Phys. Discuss., 7, 13 773-13 803, 2007. 